\title{
Dimensões De Um Conflito Ficcional: A Relação Entre Estado e o Interesse Privado A Partir Do Setor Elétrico, E Da Consolidação Da Espírito Santo
}

\section{Centrais Elétricas S/A.}

\author{
Dimensions of a Fictional Conflict: The relationship between State and private interest since the Electric Sector, \\ and the consolidation of Espirito Santo Centrais Elétricas $S / A$.
}

Jayme K. R. Lopes ${ }^{1}$

\begin{abstract}
RESUMO
A construção de um setor de energia elétrica estatal e nacional, ocupou um papel especial na história do desenvolvimento do Estado brasileiro entre as décadas de 1940 e 1980. Neste contexto, o setor foi um dos lugares de busca por controle político sobre a administração pública, e de ganhos econômicos a partir um desenvolvimento industrial que se consolidava. Este artigo, utilizando um recorrido de dados históricos, teóricos e bibliográficos, se propõe esta conjuntura explorando o caso do Estado do Espírito Santo. Jogando luz, sobretudo, ao entrelaçamento das ações do Estado e do interesse privado na implementação de sua infraestrutura elétrica e no processo de consolidação da empresa estatal de energia elétrica, a ESCELSA (Espírito Santo Centrais Elétricas S/A).
\end{abstract}

PALAVRAS CHAVE: Escelsa, Energia, Estado, Capitalismo

\begin{abstract}
The construction of a state-owned and national electric energy sector, played a special role in the history of the development of the Brazilian State between the 1940s and 1980s. In this context, the sector was one of the places of search for political control over public administration, and economic gains from a consolidated industrial development. This article, using a range of historical, theoretical and bibliographic data, proposes this situation by exploring the case of the State of Espírito Santo. Shedding light, above all, on the intertwining of State actions and private interest in the implementation of its electrical infrastructure and in the process of consolidation of the state-owned electricity company, ESCELSA (Espírito Santo Centrais Elétricas S/A).
\end{abstract}

KEYWORDS: Escelsa, Energy, State, Capitalism

\footnotetext{
1 Prof. Substituto - Departamento de Ciências Sociais - Universidade Federal do Espírito Santo (UFES), doutorando em Ciências Sociais - PUC-Rio, mestre em Antropologia Social - FLACSO. E-mail: jaymekrlopes@gmail.com; Currículo Lattes: http://lattes.cnpq.br/5875441438910836.
} 


\section{INTRODUÇÃO}

Este artigo busca explorar a implementação e expansão da energia elétrica no Estado do Espírito Santo, que ocorreu entre as décadas de 1940 e 1970. A consolidação do setor elétrico se traduziu em grandes investimentos estatais direcionados a área de geração, transmissão e distribuição de energia elétrica, onde o Estado foi protagonista com a criação de grandes empresas estatais.

Contudo, a necessidade de grandes investimentos públicos e ao mesmo tempo, de conhecimento técnico e suporte político no âmbito estadual e nacional, estabeleceram uma cadeia de dependências entre os interesses de diversos atores das elites políticas, grupos econômicos e a administração pública. Nesta conjuntura, ao que nos parece, não há a possibilidade de dimensionar os limites e as fronteiras das esferas do interesse público e privado.

Como veremos, a necessidade de sobrevivência de um status quo político, em um momento histórico de rupturas e adaptações a um novo ciclo econômico de caráter internacional, de forte dependência dos Estados nacionais, é o ponto chave, que predominou nas relações locais naquele momento. E o setor elétrico, foi peça fundamental deste cenário.

É assim, que o governador capixaba Carlos Fernando Monteiro Lindemberg na década de 1960, enfatiza a necessidade de novos recursos para a instalação do sistema elétrico estadual e sua essencialidade para a consolidação do planejamento econômico do Estado do Espírito Santo da época, em mensagem ele diz: "O progresso da Escelsa está ligado ao progresso do Espírito Santo de modo constante e indissoluvel: são dois organismos em simbiose".

A ESCELSA, como empresa pública estadual de produção, transmissão e distribuição de energia, nasceria com plena capacidade de funcionamento e investimento em 1968, a partir da fusão com a CCBFE (Companhia Central Brasileira de Força Elétrica) do grupo estadunidense American \& Foreign Power Company (ANFORP).

A nova empresa estatal, botava em prática os ideários do intervencionismo estatal e do desenvolvimentismo que se afirmavam nacionalmente, ajudando a determinar uma guinada produtiva nos setores da economia do Espírito Santo rumo a industrialização. Isto porque boa parte da agricultura cafeeira, principal fonte de renda, de organização social e política do território capixaba, havia sido dizimada por uma crise que se arrastava a décadas.

Por este caminho, se produz um rápido movimento de construção do aparelho econômico de Estado, de forma centralizada e nacionalmente articulada, que foi crucial para a criação de um capitalismo industrial e de um Estado capitalista no Espírito Santo. 
Cadernos de Estudos Sociais e Políticos, Rio de Janeiro, vol. 6, 2018.

As múltiplas faces deste processo incluem a organização das estruturas de um Estado-nação que incorporou aparelhos regulatórios e peculiaridades intervencionistas que estabeleceram um suporte ao avanço da acumulação industrial contribuindo (1) a sedimentação das cidades como lugares de conflito e transformação social, (2) firmaram a ascensão das massas - sobretudo urbanas - em algum tipo de participação política e acesso a direitos, e (3) incorporaram nas estruturas estatais Brasileiras as logicas da acumulação capitalista.

A estratégia de desenvolvimento do Espírito Santo vai buscar em sua posição geográfica um trunfo, dentro de um contexto nacional e internacional, mas também, vai se relacionar com a incorporação sistemática em seu núcleo da participação de entidades coorporativas, sobretudo, a FINDES (Federação das Indústrias do Espírito Santo).

Uma organização diretamente relacionada aos interesses coorporativos patronais que contava com a participação da elite política local, do governador, além de representantes de Bancos, Comercio, Associações Rurais e do CREA, e que intensificaria sua influência nas ações governamentais a partir do regime político ditatorial de 1964.

\section{A IMPLEMENTAÇÃO DA ENERGIA ELÉTRICA NO ESPÍRITO SANTO}

Diferente dos outros estados da região Sudeste no que diz respeito a evolução de sua economia, o Espírito Santo nasce para a conjuntura nacional somente a partir da cultura cafeeira. Em números, o café era a atividade principal para 75\% das suas propriedades agrícolas, que geravam 50\% do total da renda interna bruta em 1950.

A cultura do café foi marca de uma forma particular de expansão da atividade econômica, ocupação territorial e formação social capixaba². Diferentemente de São Paulo, onde o capital de comercialização do produto financiou a industrialização e a modernização econômica, no Espírito Santo, a importância da cultura cafeeira se dá pela particularidade de um modelo econômico e social, baseado na pequena propriedade familiar, onde subsistência e a geração de excedente conviviam de forma quase harmoniosa.

Assim, a industrialização no território capixaba vem como decorrência de uma severa crise da cafeicultura que se arrastaria até o final da década de 1960. Situação que propiciou a aproximação entre elites locais afetadas pela crise, nacionais que já participavam do processo de industrialização e a administração Federal, para a construção do aparato necessário para sustentar a uma

2 Ver CALIMAN, 2012. 
Cadernos de Estudos Sociais e Políticos, Rio de Janeiro, vol. 6, 2018.

infraestrutura de modernização no Estado. A expansão da infraestrutura de energia elétrica, era uma das condições para este processo.

No entanto, a história da implementação da energia no Espírito Santo começa ainda início do século XX A primeira usina hidrelétrica capixaba pertenceu à empresa pública estadual de serviços reunidos de Vitória, fazendo captação de água do Rio Jucu ainda nos primeiros anos do século XX. A hidrelétrica do Jucu foi construída visando a instalação de pequenas fabricas previstas no planejamento do Governo Jerônimo de Souza Monteiro (1908-1912).

Esta energia também movia as bombas do sistema de esgoto, do transporte férreo da capital Vitória. O impulso da capital fez também com que o Sul do Espírito Santo, área industrialmente mais desenvolvida do estado na época, ampliasse sua produção de energia elétrica para atender a demanda industrial do vale do Itapemirim. A usina de Fruteiras, no rio do mesmo nome, foi construída pelo governo do estado através de sua empresa de serviços Reunidos de Cachoeiro de Itapemirim.

Segundo Ribeiro (2013), os empresários capixabas entre as décadas de 1900 e 1930 também investiram nos serviços de geração e distribuição de eletricidade. Como na região sul do estado, com a Companhia de Eletricidade Muqui do sul e a Usina Hidrelétrica Aparecida, no rio Muqui do Sul, que funcionava com dois grupos de geradoras. Outros lugares do estado também operaram neste mesmo contexto.

Contudo ainda no governo Monteiro, que as companhias públicas Serviços reunidos de Vitória e a Serviços Reunidos de Cachoeiro de Itapemirim, principais empresas de energia da época, também foram colocadas nas mãos de empresários privados, por falta de capacidade da administração pública em atender à crescente - ainda que pequena - demanda.

Poucos anos depois, no governo Florentino Ávidos (1924-1928), há a retomada do controle das empresas e a construção de usinas públicas justamente pelos mesmos motivos, só que desta vez pela incapacidade de atendimento da demanda das empresas privadas. O plano de Ávidos era estimular o crescimento industrial na capital e no sul do Espirito Santo. Por isso era necessário aumentar a infraestrutura produtiva de eletricidade de modo que a carência de energia não atrapalhasse o surgimento das indústrias previstas pelo governo.

O governador atuava sob forte pressão popular e da imprensa para que o suprimento de energia elétrica fosse melhorado e ampliado. A imprensa inclusive, ajudou a organizar grupos populares que saiam pelas ruas para protestar contra a precariedade dos serviços elétricos da capital $^{3}$. Contudo, novamente em 1927, ainda na gestão de Florentino Ávidos, acontece a renúncia aos serviços de energia elétrica, com o Estado transferindo a empresa Serviços Reunidos de Vitória

$3 \quad$ Ver mais em Ribeiro (2013, pg. 45) 
Cadernos de Estudos Sociais e Políticos, Rio de Janeiro, vol. 6, 2018.

a parte da Serviços reunidos de Cachoeiro de Itapemirim, com concessão de exploração por 50 anos.

Neste momento a General Eletric S/A obrigava-se a fornecer energia elétrica as usinas industriais por preços e prazos previamente definidos. Mas a General Eletric S/A cede seus direitos a Companhia Central Brasileira de Força Elétrica-CCBFE, empresa do grupo American \& Foreing Power Company (Amforp), subsidiaria para a américa latina do grupo Eletric Bond Share, ambos dos $\mathrm{EUA}^{4}$. A CCBFE seria chamada pelos capixabas de Central Brasileira persistindo assim até 1968.

Diferente dos períodos anteriores, houve a efetiva dinamização do serviço de energia na década de 1930 com a concessão a iniciativa privada, no caso, internacional. A CCBFE inclusive, incentivou o consumo de eletricidade, vendendo produtos eletrotécnicos e fornecendo crédito a população para a compra destes produtos. Neste momento os hábitos urbanos começavam começaram a se sobrepor ao hábito rural, principalmente em Vitória.

\section{ELETRICIDADE NO CONTEXTO DA MODERNIZAÇÃO CAPIXABA}

Em 1940, o Espírito Santo já possuía uma população de 750.107 habitantes, um crescimento de aproximadamente $60 \%$ com relação ao início da década de $1920^{5}$. Este aumento populacional considerável, também era reflexo das mudanças econômicas e sociais que se colocavam, sobretudo, o crescimento urbano. Acompanhando também um cenário nacional de desenvolvimento de uma indústria de base, é concebido o projeto da Companhia Vale do Rio Doce $(\mathrm{CVRD})^{6}$ uma das primeiras empresas estatais brasileiras e bastante importante no contexto da modernização capixaba.

A CVRD, foi fruto de acordos entre os governos do Brasil, da Inglaterra e dos Estados Unidos da América, para viabilizar um suprimento de minério de ferro as forças armadas aliadas durante a Segunda Guerra. Pelo acordo, ao Brasil caberia desapropriar a Estrada de Ferro VitóriaMinas e liquidar todos os débitos e hipotecas. Aos ingleses coube indenizar a desapropriação da concessão das minas de ferro da Cia. Itabira de Mineração, que seriam incorporadas à CVRD.

\footnotetext{
4 Ferreira (et al., 2012) aponta que a inserção da AMFORP na América Latina se deu antes de sua constituição como empresa. Sua origem remonta ao período de industrialização norte-americana, com a criação da Electric Bond \& Share - resultado da fusão de duas outras companhias, a Edison General Electric Company e a Thomson-Houston - em 1892, subsidiária da General Electric.

5 Fonte: Censo Demográfico 1872, 1890, 1900, 1920,1940, 1950, 1960,1970, 1980,1991, 2000 e 2010. IBGE, 2010. Disponível em: https://censo2010.ibge.gov.br/sinopse/index.php?dados=4\&uf=00 Acesso em: 04/05/2020.

6 A Companhia Vale do Rio Doce foi criada em 1 de junho de 1942, Itabira, Minas Gerais.
} 
Cadernos de Estudos Sociais e Políticos, Rio de Janeiro, vol. 6, 2018.

Finalmente, o Export-Import Bank do Estados Unidos da América (EXIMBANK) foi designado para financiar US\$14 milhões em créditos para compras de equipamentos e materiais necessários às obras de reestruturação e ampliação da Estrada de ferro, à expansão e conclusão das obras do cais de embarque do porto de Paul (Vila Velha) e à extração do mineral nas jazidas em Minas Gerais.

Dados referentes ao trânsito de passageiros da Estrada de Ferro Vitoria - Minas ${ }^{7}$ administradas pela CVRD, demonstram o crescimento da mobilidade da população capixaba no período, em 1940 viajavam 269629 pessoas, na década de 1950 o número de passageiros chegava a 1231588. Este crescimento indica o entrelaçamento entre o aumento da mobilidade, o crescimento urbano e o aumento da demanda de energia, com o desenvolvimento industrial.

Com este contexto, para atender os 32 municípios existentes no Estado, o setor elétrico capixaba contava com 44 pequenas empresas que operavam 45 usinas geradoras. A maior e mais expressiva empresa continuava sendo a CCBFE, responsável por fornecer $92,11 \%$ da força e 74,32\% da energia gasta em iluminação nas cidades capixabas entre 1940 e 1960 (RIBEIRO, 2013 pg. 64)

Em Vitória, os maiores consumidores eram serrarias, beneficiadoras de café, as fabricas de tecidos Jucutuquara Industrial Ltda, fábrica de gelo e oficinas, como as áreas operacionais mecânicas das indústrias e das empreiteiras de obras no Porto de Vitória e da Companhia Estrada de Ferro Vitória-Minas.

Já em Cachoeiro de Itapemirim, quatro serrarias de madeira e três fabricas uma de tecido, outra de cimento e de açúcar utilizavam a energia elétrica. Todo este consumo tanto na capital quanto em Cachoeiro era fornecido pela CCBFE. A expansão industrial e comercial associada a indução do consumo residencial, extrapolava a capacidade geradora da Central Brasileira e reacendia na população os mesmos protestos do passado.

Ainda em 1941, o sistema de geração da CCBFE começa a dar os seus primeiros sinais de deficiência. A demanda média anual de energia na zona de concessão da CCBFE, que correspondia a 32,89\% da população capixaba e compreendia a zona mais dinâmica da sua economia aumentou, sem que empreendimentos de geração acompanhassem a demanda. Tendo em vista o cenário, o interventor federal escolhido por Getúlio Vargas, Jones dos Santos Neves (1943-1945) inclui na tríade de planejamento da ação de seu governo, que se baseava em saneamento, produção e transportes, um programa para enfrentar a crise no abastecimento de energia.

As diretrizes de Neves eram claras e anunciavam um novo tempo para ação estatal e para a responsabilidade sobre a infraestrutura elétrica capixaba: "Os novos tempos nos ensinam que o

\footnotetext{
7 Obtidos em ARARIPE, D. Alencar. História da Estrada de Ferro Vitória a Minas 1904-1954. Companhia Vale do Rio Doce. Rio de Janeiro, 1954.
} 
Cadernos de Estudos Sociais e Políticos, Rio de Janeiro, vol. 6, 2018.

Estado é a função das condições econômicas que predominam em sua organização social. Daí a necessidade imperiosa de fortalecer as suas forças econômicas e racionalizar a sua administração."»

\section{INTERVENCIONISMO ESTATAL}

Segundo Zorzal e Silva (2003), as distintas formas de desenvolvimento do capitalismo marcam diferentes formatos de institucionalização, caracterizando tipos específicos de aparatos de Estado. Na literatura que trata dos processos históricos de desenvolvimento do capitalismo o divisor de águas que distingue cada estágio e respectivos rótulos que caracterizam a institucionalidade vigente, é entendido a partir da variável intervenção estatal em suas diversas modalidades.

O capitalismo especialmente na América Latina não é um elemento histórico determinado, que preceda uma organização e uma consequente regulamentação estatal. Isso tem uma consequência, sobretudo, na configuração da ordem social, já que é o Estado que assume a tarefa de instaurar uma sociedade moderna.

Desta conjuntura, vem a especificidade de um intervencionismo estatal dedicado a executar um modelo de desenvolvimento para a sociedade em conjunto. A intervenção do Estado neste contexto não corresponde, no entanto, a uma função corretiva do mercado como um esforço deliberado de promover o desenvolvimento econômico e social. Implicando, a dependência da economia de mercado da iniciativa estatal e da razão de existência do Estado.

Tanto para Peter Evans (1993), como para outros autores que analisam a lógica estatal e nas suas capacidades, os aparatos de Estado podem ser utilizados para promover o desenvolvimento capitalista nos países do sul global, sendo um dos principais encargos do Estado acelerar a industrialização, a modernização econômica, bem como, a infraestrutura urbana.

Embora haja especificidades, pode-se dizer que a dimensão econômica dos processos sociais expressa no axioma do desenvolvimento industrial o seu status predominante, sobretudo a partir da capacidade estratégica dos Estados, para administrar o exercício político (CONTRERAS, 1994, p.11), tanto a partir da dimensão conflituosa, quando a partir de uma situação de cooperação.

O período pós-guerra, em termos do desenvolvimento capitalista, foi marcado pela hegemonia de um consenso keynesiano, produzindo uma ativa intervenção do Estado na economia. A partir de tal cenário ideológico e intelectual, reforçou os fundamentos intervencionistas da estratégia desenvolvimentista nos países da América Latina e no Leste Asiático.

$8 \quad$ Ver mais em Ribeiro (2013, pg. 72) 
Cadernos de Estudos Sociais e Políticos, Rio de Janeiro, vol. 6, 2018.

O desenvolvimentismo aparece na literatura tanto referindo-se a um fenômeno da esfera do ideológica, como para nomear práticas históricas de política econômica associadas a um Estado característico. A primeira referência de "Estado desenvolvimentista" pode ser encontrada em Cardoso e Faletto (1970), entre o final da década de 1960 e o início da década de 1970. Todavia, a caracterização de "Estado-desenvolvimentista" já aparecera antes com Hélio Jaguaribe (1962) na obra Desenvolvimento econômico e desenvolvimento político.

Ricardo Bielschowsky (1988), fornece uma análise precisa das características do ideário nacional-desenvolvimentista, onde: (1) a industrialização integral é o caminho de superação da pobreza; (2) não é possível uma industrialização eficiente e racional através do mercado; (3) no qual o planejamento estatal é que tem que definir a expansão dos setores econômicos e (4), cabe ao Estado ordenar a expansão, captar a orientação e ordenar os recursos financeiro, onde a iniciativa privada for incapaz.

\section{A CONSTRUÇÃO DO ESTADO DESENVOLVIMENTISTA CAPIXABA E A INSTITUCIONALIZAÇÃO DA ENERGIA ELÉTRICA}

No Brasil, o industrialismo e o "desenvolvimentismo" como estratégia de intervenção, entram para a estrutura estatal no período entre 1946 e 1964․ É possível dizer que este "desenvolvimentismo" segundo Fonseca (2015), vai se localizar entre duas questões duas dimensões do ponto de vista epistemológico: (1) um conjunto de práticas de política econômica propostas e executadas pelos formuladores de políticas que compartilham um núcleo comum de atributos que os caracteriza como tal e (2) um conjunto de ideias que se propõe a expressar teorias, concepções ou visões de mundo.

Ainda segundo Fonseca (2015), estas concepções na busca por uma capacidade de construir tipo ideal mundo, foram utilizadas por vários autores para conceituar não propriamente o desenvolvimentismo, mas o Estado desenvolvimentista. O que Esteban Echevarría (1964) denominou "mecanismo essencial" para à superação do subdesenvolvimento.

Dentro desta conjuntura, o Espírito Santo segundo Marta Zorzal e Silva $(1986)^{10}$, principalmente no contexto da eleição pós-Vargistas 1947, abre os caminhos para uma intervenção estatal maciça e centralizada, começam a ser abertos. Foi também, a primeira oportunidade de participação política de novas forças sociais, como pequenos e médios agricultores e uma pequena

$9 \quad$ No primeiro governo Getúlio Vargas chamado "nacional-desenvolvimentismo".

10 SILVA, Marta Z. Espírito Santo: Estado, Interesses e Poder. Dissertação. FGV, Rio de Janeiro, 1986. 
Cadernos de Estudos Sociais e Políticos, Rio de Janeiro, vol. 6, 2018.

classe urbana, mesmo que, o modelo de relação e articulação dos candidatos e partidos em disputa continuasse a mesmas. Até então, a luta se travava entre apenas dois conjuntos de forças políticas: classes agro fundiárias e classes mercantis-exportadoras.

A vitória dada ao candidato do PSD ${ }^{11}$, Carlos Lindenberg (1947 a 1950) $)^{12}$ nesta primeira eleição, que nutria forte relação inter-coroneis, mostrava este panorama. Ainda segundo Silva, em termos comparativos com a região sudeste, onde a prática populista passava a ser o norteador da vida política neste momento, no Espírito Santo, as práticas coronelistas são requentadas e constituem o domínio político da época. Já a disputa política das eleições de 1950, que elegeu Jones dos Santos Neves (1951 a 1955), para além de questões estaduais, havia aquelas de ordem do relacionamento inter-elites no plano regional, como em termos da solidariedade política com as demais elites no plano nacional.

O resultado deste pleito eleitoral, apesar das características eminentemente rurais do eleitorado capixaba, refletiu o atendimento aos interesses das classes trabalhadoras dos grandes centros do país, com forte presença da retorica desenvolvimentista. Importante observar que os dados populacionais do período entre 1920 e 1950 reforçam a análise de um crescimento populacional da capital e da região metropolitana da Grande Vitória em torno de 117\% e apenas entre 1950 e 1960, de 82\%, enquanto a população rural, mesmo que ainda predominantemente rural, passou de $71,8 \%$ em 1960, para 54\% em $1970^{13}$.

Este governo de Jones dos Santos Neves, se produziu a partir da materialização de um projeto de modernização para o Espírito Santo, produzindo as condições para a sua implementação, a partir da ideia de necessidade de uma infraestrutura adequada. Todavia como problemática fundamental, se colocava dissociação entre a instância do agente político (Estado) e as demais instancias (econômica e sociais) em um contexto local de população predominante rural e uma economia agro fundiária. O que leva em muitos momentos a Jones, mesmo tendo como plataforma política a época de sua eleição, uma aliança com a oligarquia agro fundiária, a atender apenas as necessidades básicas deste grupo em detrimento a continuidade do projeto de governo ${ }^{14}$.

A criação do primeiro Plano Estadual de Eletrificação em 1951, é uma das manifestações deste cenário, com uma intensa participação das elites políticas e econômicas capixabas, tendo como pilares a construção de uma Hidroelétrica e a criação de uma empresa estadual de energia, que nas palavras de Jones dos Santos Neves, seria "o fundamento inicial da nossa redenção econômica".

\footnotetext{
$11 \quad$ Partido Social Democrata.

12 Os membros e apoiadores do PSD faziam parte de uma elite latifundiária, sobretudo as que dominavam a produção do café. Essa característica fazia com que a influência do partido incidisse tanto nas áreas urbanas quanto nas rurais. (ALVARENGA, 2017).

13 BITTENCOURT, 1984.

14 Ver mais em SILVA, 1996 pg. 436. WEBER, 1992
} 
Cadernos de Estudos Sociais e Políticos, Rio de Janeiro, vol. 6, 2018.

Foram as articulações entre Neves, Getúlio Vargas e Oswaldo Aranha em 1954, que fizeram com que o recém-criado BNDE (Banco Nacional do Desenvolvimento Econômico) assumisse o pagamento integral da construção da hidrelétrica de Rio Bonito e de linhas de transmissão. Em contrapartida, o Governo do Estado, teria por obrigação contratual organizar a formação da Espírito Santo Centrais Elétricas S/A.

Como aponta Marta Zorzal e Silva (1986), ao mesmo tempo, foram implementados os mecanismos institucionais para o funcionamento de um processo contínuo de industrialização da economia. Ocorrem significativas modificações nos órgãos considerados chaves da administração pública, como a criação da Secretaria de Viação e Obras Públicas, com o intuito de execução de sua política econômica. Esta secretaria, foi equipada tecnicamente com engenheiros dos Estados vizinhos e absorveu a maior parte dos recursos financeiros do Estado, em média 42,7\%.

O papel da energia elétrica neste contexto da modernização brasileira segue a dinâmica citada por Alexandre Saes $(2008)^{15}$ :

\begin{abstract}
"conjugado com a emergência do processo de industrialização e urbanização, as transformações no sistema de eletricidade eram parte fundamental na formação do capitalismo brasileiro. As decisões e os projetos políticos para o desenvolvimento do setor de energia elétrica representavam, no limite, as formas como as classes dominantes do país pensavam no grau de subordinação ao capital estrangeiro e a intensidade da modernização”.
\end{abstract}

No caso capixaba, em 1952 Jones dos Santos Neves (PSD), quando analisa os propósitos da política elétrica e sua relação com os eixos de modernização capixaba diz: “(...) a eletrificação do Estado obedece ao proposito estabelecido nas diretrizes do atual governo de preferência as centrais que mais se aproximem dos eixos de gravidade econômica." E complementa no mesmo discurso:

\footnotetext{
“(...) situação estratégica de seu porto de mar (...) tendo como tributarias as regiões de todo o 'hinterland' mineiro, o crescente caudal de minério de ferro que desce das vertentes do Itabira em busca do oceano para se encontrar com o carvão importado, tudo isso faz deste litoral um centro monopolizador de futuras industrias ${ }^{16 "}$.
}

Período em que ao mesmo tempo, aos debates sobre o acesso à energia elétrica se intensificavam, e que o setor elétrico passa a ser dotado de instrumentos de planejamento e financiamento de sua infraestrutura como o BNDES, Fundo Estadual de Eletrificação, Fundo

15 SAES, Alexandre. Conflitos do capital: Light versus CBEE na formação do capitalismo brasileiro (18981927). Campinas: tese de doutorado - UNICAMP, 2008

16 Espírito Santo (Estado). Governador 1952, 1953, 1954. Vitória: Impressa Oficial apud. Silvia, op. cit., p.261, 262 , nota 29. 
Cadernos de Estudos Sociais e Políticos, Rio de Janeiro, vol. 6, 2018.

Federal de Eletrificação e a Eletrobrás, que vinha sendo discutido desde 1944, com o Plano Nacional de Eletrificação.

Investimentos em energia elétrica, rodovias e portos foram considerados fundamentais no Espírito Santo, bem como o aparelhamento do estado enquanto ente capaz de planejar e prover o sistema de suporte institucional, fiscal e financeiro.

Neste ponto, é possível caracterizarmos inicialmente este Estado-empresário como categoria de dominação racional legal, onde Max Weber observa com forma de dominação típica do estado moderno.

Entendemos ele como lugar da existência de normas legais formais, abstratas e universais e do ponto de vista da estrutura, pela existência de um conjunto administrativo burocrático. Weber inclusive, não considera este tipo de contexto um modelo de dominação estático e sim historicamente dinâmicos, onde se colocam pressupostos importantes para os potenciais conflitos que possam existir entre a atividade política e a administração pública.

A conjuntura nacional-desenvolvimentista vigente nos governos Getúlio Vargas deu a Jones do Santos Neves, o argumento básico para propor esta ação intervencionista no Espírito Santo. O modelo econômico que se colocava, com mais intensidade na região da capital Vitória, se baseava no uso maciço de eletrodomésticos e produtos eletrotécnicos, além do automóvel.

O reforço dessa tendência vem com o aterro de mangues, enseadas, desmonte de morros e consequente construção de novas avenidas e o porto de Vitória. Também se constitui o aeroporto, prédios comerciais à beira-mar, loteamentos. Neste momento, o Plano de Valorização Econômica do Estado em 1950, concentrava 39\% da capacidade de investimento estatal em cinco anos.

A concepção autoritária de Estado presente nos grupos de poder oligárquicos capixabas converteu-se em o que Marta Zorzal e Silva (1986) chama Estado Social ${ }^{17}$, tendo como diretriz a uma proposição industrializante. Segundo Zorzal e Silva, é onde o espaço das relações políticas não foi pautado pela ruptura, mas pela materialização de um planejamento econômico intervencionista articulado com os diversos grupos de poder regionais e nacionais, como única saída para o provimento de um desenvolvimento socioeconômico e atendimento das respectivas agendas de interesse.

O planejamento enquanto instrumento de poder em uma sociedade sob a ordem da demanda agro fundiária, se tornaria a composição principal do jogo para ocupação da administração pública. A formação da ideia de política econômica do Estado neste caso, é um

${ }_{17}$ O Estado-Social, observado por Marta Silva diz respeito a planificação do desenvolvimento não só a partir da administração pública, mas também a partir dela, através de novas práticas na gestão da educação, assistência social, cultura entre outros aspectos da vida social. 
Cadernos de Estudos Sociais e Políticos, Rio de Janeiro, vol. 6, 2018.

campo de luta onde se decide a centralidade dos interesses de classe tendo como resultado, a relação de forças e conflitos entre grupos dominantes ${ }^{18}$.

A ESCELSA despontaria pela primeira vez em 1956, absorvendo pequenas empresas de geração, transmissão e distribuição, suprindo as deficiências de abastecimento da zona de concessão da Companhia Central Brasileira de Força Elétrica (CCBFE).

\section{O APROFUNDAMENTO DA CRISE DO CAFÉ E O “CONSENSO" PELA INDUSTRIALIZAÇÃO}

Não é possível compreender a consolidação da infraestrutura elétrica no Espírito Santo, bem como seu processo de modernização e industrialização, sem levar em consideração a crise da agricultura cafeeira.

Segundo José Buffon, entre a década de 1940 e 1950, se chega ao máximo da expansão da cafeicultura no estado. Ao mesmo tempo, que esgotando-se as fronteiras agrícolas, pragas, um programa nacional de erradicação e finalmente, que novos setores da economia capixaba ganham dinamismo e logo, que aceleram a falta de mão de obra. Praticamente uma tempestade perfeita, que tem seu desfecho nos primeiros anos da década de 1960, com o declínio derradeiro do cultivo.

Para Ueber de Oliveira (2018), acentuada pelas características do cultivo de café no Espírito Santo, especialmente, de produção agrícola familiar e em pequenas propriedades, a crise causada pelo café levou a grande desorganização da economia capixaba. Entre 1962 e 1967, foram erradicados 53,8\% dos cafeeiros capixabas, gerando a eliminação de 60 mil empregos, e o que equivaleu a 200 mil pessoas migrando campo para a cidade. ${ }^{19}$

O cenário, levou as elites capixabas - sobretudo aquelas ligadas ao café, hegemônicas até então - afetadas enormemente com a consequente perda da capacidade política, a constatação da necessidade de diversificação profunda da economia, o que Oliveira (2018) chama de "consenso de necessidades".

Não existia opção para os grupos de poder político e econômico capixaba, a não ser confluir para um profundo projeto industrializante gestado por elas próprias e sob o controle do $\mathrm{PSD}^{20}$. Mesmo assim, parte destas elites agrarias, perdem seu espaço dando lugar a forças com um

POPULANTZAS, 1997 e SAES, 2008.

Ver em Oliveira (2018, pg.147)

Partido Social Democrata 
Cadernos de Estudos Sociais e Políticos, Rio de Janeiro, vol. 6, 2018.

viés urbano-industrial, abraçando de forma definitiva o ideário desenvolvimentista que se colocava no país.

Esta dinâmica é corroborada por José Medina Echevarría (1964), quando analisa as questões principais na consolidação das políticas desenvolvimentistas. Para ele são necessários três pré-condições: (1) atores, grupos sociais e políticos, e suas organizações como empresários, intelectuais, burocracia estatal, elite política, operários e classes médias; (2) adoção por parte deles de uma visão de mundo a partir do ideário do desenvolvimento, e por último; (3) força política para canalização dos seus anseios e os verem materializados como política econômica.

\section{A CONCRETIZAÇÃO DO ESTADO-EMPRESÁRIO CAPIXABA}

No contexto que se apresentava, os principais jornais do Espírito Santo da época estavam longe das tensões e da histeria dos noticiários dos outros estados da região Sudeste. Para Oliveira (2018), os jornais capixabas enquanto veículos oficiais das principais elites e grupos políticos locais, mostravam que no Espírito Santo existiam outros interesses mais urgentes.

Os três primeiros meses de 1964, como exemplo, foram marcados pelo auge da encampação da Companhia Central Brasileira de Força Elétrica (CCBFE). A campanha pela encampação vem a partir do General José Parente Frota, à época, também Deputado Estadual pelo PSD. Uma parte das eleitas capixabas, incluindo Frota, viam a possibilidade de encampação parecida com a que havia ocorrido no Governo Leonel Brizola (1959-1962) no Rio Grande do Sul, porém, bastante criticado pela direita e processo pelo qual Frota expressava profunda repulsa: "para não deixar o movimento cair nas mãos de comunistas"21.

O contexto da encampação CCBFE chega as ruas e ao boicote da empresa por meio do não pagamento da conta de luz, quase levando a uma greve no setor. O principal jornal do capixaba, A Gazeta, que havia sido criado e era comandado por Carlos Fernando Monteiro Lindenberg (PSD), ex-governador, trazia matérias e palavras de ordem em favor da encampação.

Assim começa a nacionalização do setor, em 1964 com a aquisição pela Eletrobrás de todas as empresas do grupo Amforp, tem um dos teus pontos altos ${ }^{22}$. As empresas que pertenciam à Amforp e atuavam no âmbito estadual passam para o controle de seus respectivos governos estaduais, reforçando sua importância como atores de mudança locais.

\footnotetext{
21 (OLIVEIRA, 2018, pg. 66)

22 Processo concluído apenas em 1979, com a compra da Light, encerrando a participação dessas duas empresas estrangeiras no setor elétrico nacional.
} 
Cadernos de Estudos Sociais e Políticos, Rio de Janeiro, vol. 6, 2018.

Esta conjuntura tem os seus momentos cruciais com a posse do primeiro governador da ditadura, e do antigo quadro do PSD, agora da Arena, Christiano Dias Lopes (1967-1971). Vencedor do primeiro pleito indireto, Dias Lopes acentuou os objetivos desenvolvimentistas como principal política pública. Dentro disso colocou em voga o plano de construção pela Companhia Vale do Rio Doce, do porto de Tubarão e uma usina de pelotização ${ }^{23}$ e uma siderúrgica e atreladas a este porto.

Em 1968, como parte do mesmo processo, a Espírito Santo Centrais Elétricas S/A (ESCELSA) seria recriada. Agora criada detentora de plena capacidade, funcionamento e investimento, sob o controle da Eletrobrás e com suporte financeiro e político do BNDE (Banco Nacional do Desenvolvimento Econômico), GERCA (Grupo Executivo para Recuperação da Cafeicultura), CVRD (Companhia Vale do Rio Doce) e CSN (Companhia Siderúrgica Nacional).

Para além do movimento relacionado a estruturação da administração pública a partir dos atores políticos ou das elites políticas estatais, é ainda na gestão Jones dos Santos Neves, que se anexam as entidades corporativas as instancias de planejamento do Estado. Algumas delas como o conselho técnico da FINDES (Federação das Indústrias do Espírito Santo) empreenderam a elaboração de projetos de industrialização focados na siderurgia, em uma geografia industrial e no levantamento da realidade econômico-social do Espírito Santo.

A partir governo Christiano Dias Lopes e até o fim da ditadura militar, há profunda da influência da FINDES. Sendo ela a responsável por indicar diversos quadros técnicos e boa parte do secretariado do governo Dias Lopes, além de delinear as diretrizes governamentais. Inclusive, tendo como próximo governador o segundo "biônico" da história do Espírito Santo, Carlos Gehart Santos (1971-1974), oriundo dos quadros da instituição.

É na gestão de Gehart que o processo de industrialização capixaba se altera, buscando a inserção da economia capixaba na economia nacional e mundial. Neste contexto é implementado o que ficou conhecido como Grandes Projetos de Impacto (GP's) ${ }^{24}$.Os GP's ampliam o papel da Companhia Vale do Rio Doce, além de agregar os projetos de uma fábrica de celulose (ARACRUZ CELULOSE), portuária e logístico (integração com centro-oeste do país através do porto de Tubarão), naval (estaleiros) e turístico.

O que marca esta conjuntura é sobretudo, a predominância de quadros técnicoburocráticos e a transformação acelerada de uma economia agrário-exportadora, para uma industrial urbana.

Esta expansão do parque industrial capixaba e dos investimentos no setor elétrico vão acompanhar o cenário nacional e dura até a década de 1970 com o II Plano Nacional de

23 A pelotização é o processo de compressão ou moldagem do mineiro de ferro na forma de um pellet.

$24 \quad$ Ver Oliveira, 2018. 
Cadernos de Estudos Sociais e Políticos, Rio de Janeiro, vol. 6, 2018.

Desenvolvimento (PDN II), onde foram concebidos os projetos de Itaipu, Tucuruí e o Programa Nuclear.

Todavia, o financiamento externo para estes e outros projetos, em uma conjuntura externa de plena crise do petróleo, de default Mexicano de 1982 e um contexto interna de declínio do regime militar, vão levar uma das mais profunda crises no setor de energia, se arrastando até os anos 1990, quando a Escelsa, em 1995, é a primeira empresa estadual do setor de energia a ser privatizada através do Programa Nacional de Desestatizações.

\section{CONCLUSÃO}

A consolidação da energia elétrica percorre os vários caminhos da modernização no Brasil, sendo participante direto de diversos cenários da vida política, econômica e social. Por esta direção, o processo de institucionalização do setor elétrico ocorrido principalmente entre as décadas de 1940 e 1970, se mistura com a construção da estrutura do Estado-nação.

Mesmo que todo este contexto também seja filho de uma conjuntura que não foge ao script da história do ciclo do capital do mundo ocidental, remetendo aos papeis desempenhados tanto pelo Estado quanto pelos interesses privados na regulação das crises do capitalismo, a construção da modernidade brasileira e o papel da energia elétrica no fomento dos serviços públicos e industriais, estiveram especialmente ligadas a mecanismos de aquisição e/ou preservação do poder de vários grupos sejam eles econômicos ou políticos, em um contexto local ou em escala nacional.

Notadamente, a criação de instituições estatais foram peças chave no contexto de ascensão de uma política urbana em um Estado centralizado e cada vez mais complexo. Mesmo que isso não tenha significado uma ruptura efetiva nas estruturas da desigualdade social.

O que parece claro, é que o desenvolvimento da infraestrutura elétrica pode jogar luz sobre o dilema sobre a discussão do lugar do Estado na dimensão econômica e política. Sobretudo, ao serem construtoras e participantes dos regimes políticos e ao mesmo tempo, produtoras de um bem de consumo fundamental e em certos momentos escassos, para diferentes grupos da sociedade, ajudaram a transformá-la profundamente.

\section{BIBLIOGRAFIA}

ALVARENGA, J. F. Espírito Santo (1930-1943): populismo ou hegemonia oligárquica? Vitória: Anais do VI Congresso Internacional UFES/Paris-Est, 2017. 
Cadernos de Estudos Sociais e Políticos, Rio de Janeiro, vol. 6, 2018.

BIELSCHOWSKY, R. Pensamento econômico brasileiro: o ciclo ideológico do desenvolvimentismo. Rio de Janeiro: Ipea/Inpes. Série PNPE, nº19, 1988.

BIANCARELli, A. M.; CINTRA, M. A. M. (Orgs.). Presente e futuro do desenvolvimento brasileiro. Brasília: IPEA, 2015.

BUFFON, J. A. O café e a urbanização no Espírito Santo: aspectos econômicos e demográficos de uma agricultura familiar. Dissertação. Instituto de Economia, Universidade Estadual de Campinas, Campinas, 1992.

CARDOSO, F. H.; FALETTO, E. Dependência e desenvolvimento na América Latina. Rio de Janeiro: Zahar, 1970

CALIMAN, O. Formação Econômica do Espírito Santo: de Fragmentos do Período Colonial à Busca de um Projeto de Desenvolvimento. Revista interdisciplinar de gestão social, v.1 n.2 p.3763, mai./ago. 20120.

Centro da Memória da Eletricidade no Brasil. Panorama do setor de energia elétrica no Brasil. Rio de Janeiro: Memória da Eletricidade, 1988.

Centro da Memória da Eletricidade no Brasil. A vida cotidiana no Brasil Nacional: A Energia Elétrica e a Sociedade Brasileira (1930 - 1970) / Coordenação Marilza Elizarda Brito. Rio de Janeiro, 2003.

CORRÊA, M. L. O setor de energia e a constituição do estado no Brasil: o conselho nacional de águas e energia elétrica (1939-1954). Tese. Programa de Pós- Graduação em História. UFF, Rio de Janeiro, 2003.

CONTRERAS, E. C. A. Os desbravadores: a Petrobras e a construção do Brasil industrial. Rio de Janeiro: Relume Dumará/ANPOCS, 1994.

D'ARAUJO, M. C. As Instituições brasileiras da Era Vargas. Rio de Janeiro: Ed. UERJ: Ed. Fundação Getúlio Vargas, 1999. 212p. FREIRE, Ana Lucy Oliveira. Projetos de urbanização em Vitória-ES: Aspectos do processo de produção de uma metrópole moderna espaço e tempo, São Paulo, nº 15, pp. 105 117, 2004.

DRAIBE, S. Rumos e metamorfoses: um estudo sobre a constituição do estado e as alternativas da industrialização no Brasil, 1930-1960. Paz e terra, 1985.

Espírito Santo (Estado). Governador 1952, 1953, 1954. Vitória: Impressa Oficial. apud. Silva, op. cit., p. 261, 262, nota 29.

EVANS, P. Construting the 21th Century Developmental State: potentialities and pitfalls. In: O. Edigheji (ed.) Constructing a Democratic Developmental State in South Africa Potentials and Challenges. Capetown: HSRC Press.

FELICIANO, R. (Coord.) Panorama da memória da eletricidade no Brasil. Rio de Janeiro: Centro da Memória da Eletricidade no Brasil, 1988.

FELIPE, E. S.; OLIVEIRA, U. J. de. (org) Estado, elites, processos e desafios do desenvolvimento no Espírito Santo. Editora Milfontes, Serra, 2018. 
FERREIRA, A. L.; SILVA, A. F. C. da; SIMONINI, Y. Os donos da luz: sistemas de gestão e redes técnicas no território brasileiro o caso da AMFORP (1927-1939). In: Anais do Simposio Internacional Globalizacion, innovación y construcción de redes técnicas urbanas en América y Europa, 1890-1930. Brazilian Traction, Barcelona Traction y otros conglomerados financieros y técnicos. Universidad de Barcelona, Faculdad de Geografía y Historia. Barcelona, 2012, ES.

FONSECA, P. C. D. Desenvolvimentismo: a construção do conceito. In: CALIXTRE, A. B.; MEDINA ECHAVARRÍA, José. (1964), Consideraciones sociológicas sobre el desarrollo económico. Buenos Aires, Solar Hachette.

HIRSCHMAN, A. O. Os conflitos sociais como pilares da sociedade de mercado democrática. Novos Estudos CEBRAP, São Paulo, v.3, 1994.

JAGUARIBE, H. Desenvolvimento Econômico e Desenvolvimento Político. Rio de Janeiro: Editora Fundo de Cultura, 1962.

LESSA, C. 15 anos de política econômica. São Paulo: Brasiliense, 1982.

OLIVEIRA, U. J. de. Elites capixabas no golpe de 1964: o bipartidarismo e a convergência de agendas desenvolvimentistas (1964-1982). Editora Milfontes, Serra, 2018.

POPUlANTZAS, N. Political Power and Social Classes, New Left Books, London: 1973.

RIBEIRO, Luiz Cláudio M. Excelsos destinos: história da energia elétrica no Espírito Santo 18961968 EDUFES. Vitória, 2013.

RIBEIRO, D. A. Planejamento e industrialização no espírito santo: o conselho de desenvolvimento econômico do espírito santo (CODEC). Anais do VI Congresso Internacional UFES/Paris-Est, 2016.

SAES, A. M. Conflitos do capital: Light versus CBEE na formação do capitalismo brasileiro (18981927). Tese. Instituto de Economia da UNICAMP, Campinas, 2008.

Luz, leis e livre-concorrência: conflitos em torno das concessões de energia elétrica na cidade de São Paulo no início do século XX. Scielo, História vol.28 no.2. Franca, 2009. Disponível em: http://www.scielo.br/pdf/his/v28n2/08.pdf

SILVA, M. Z. E. Espírito Santo: Estado, Interesse e Poder. Dissertação. Escola Brasileira de Administração Pública, FGV. Rio de Janeiro, 1986.

EDIUFES, Vitoria, 2004

Vale do Rio Doce na estratégia do desenvolvimento brasileira. 